\title{
Fractal Characteristics of Coal and Sandstone Failure under Different Unloading Confining Pressure Tests
}

\author{
Tianran $M a \mathbb{D}^{1},{ }^{1,2}$ Depeng $M a \mathbb{D}^{3},{ }^{3}$ and Yongjie Yang $\mathbb{D}^{4,5}$ \\ ${ }^{1}$ State Key Laboratory for Geomechanics and Deep Underground Engineering, China University of Mining and Technology, \\ Xuzhou 221116, China \\ ${ }^{2}$ School of Mechanics and Civil Engineering, China University of Mining and Technology, Xuzhou 221116, China \\ ${ }^{3}$ College of Water Conservancy and Civil Engineering, Shandong Agricultural University, Tai'an 271018, China \\ ${ }^{4}$ College of Mining and Safety Engineering, Shandong University of Science and Technology, Qingdao 266590, China \\ ${ }^{5}$ Key Laboratory of Mining Disaster Prevention and Control, Qingdao 266590, China
}

Correspondence should be addressed to Depeng Ma; yr950726@yeah.net

Received 13 August 2019; Revised 27 December 2019; Accepted 23 January 2020; Published 15 February 2020

Academic Editor: Davide Palumbo

Copyright (c) 2020 Tianran Ma et al. This is an open access article distributed under the Creative Commons Attribution License, which permits unrestricted use, distribution, and reproduction in any medium, provided the original work is properly cited.

To analyze the fractal characteristics of coal rock failure under unloading conditions, triaxial unloading confining pressure tests were carried out on coal and sandstone rock samples under different unloading rates and initial confining pressures. We examined the distribution of the surface cracks and fragmentation of the coal and sandstone samples that failed under different triaxial unloading confining pressure tests. The results showed that the fractal dimension of the surface cracks in coal and sandstone decreased as the initial unloading confining pressure increased. Thus, shear failure is more obvious in coal or sandstone with highstress conditions caused by unloading confining pressure than in coal or sandstone with low-stress conditions. However, the fractal dimension of the surface cracks increased with the unloading rates. Additionally, the fractal dimension of the fragmentation in the coal and sandstone samples had a negative correlation with the initial unloading confining pressure. When the initial confining pressure was relatively low, the samples underwent splitting and shear failure; when the initial confining pressure was higher, the failure mode was mostly shear failure and the fragmentation of the samples was less homogeneous. In contrast, the fractal dimension of the fragmentation in the coal and sandstone increased with higher unloading rates. The lithology had a significant effect on the fractal dimension of the surface cracks and on the fragmentation. Samples with more internal fissures had more surface cracks and the fragmentation was more homogeneous when the rock failed compared with samples with less fissures under the same experimental conditions.

\section{Introduction}

In the past decade, large-scale excavation of rock mass for engineering projects under high in situ stress conditions has presented rock mechanics problems for engineering geologists involved in infrastructure construction and mining in China. General engineering practice shows that large-scale underground excavation can lead to unloading of the rock mass. In particular, the mechanical behavior of the highly stressed rock under loading is significantly different from that under unloading conditions $[1,2]$. Mines in China are extracting coal from deeper mining depths, and coal mines enter the deep mining stage gradually. This results in a series of adverse conditions, including high rock pressure, large water inflow, and high ground temperature. Thus, it is important to develop deep coal resources safely and efficiently [3-6]. In the coal mining process, confining pressure is unloaded from the rock mass, which often leads to coal mine disasters such as structural instability and rock burst $[7,8]$. Therefore, there is an urgent need to investigate the mechanical behavior of coal and rock during the unloading process. To date, researchers have analyzed various factors affecting the unloading mechanical behaviors of coal and rock, including the unloading path, unloading rate $[9,10]$, and initial unloading confining pressure [11, 12]; many significant results have been obtained [13-15]. 
Fractal geometry is used to describe irregular and disorderly phenomena in nature. Since Mandelbrot firstly established fractal geometry in 1982, our understanding of natural phenomena has developed beyond conventional geometry such as lines (one-dimensional), surfaces (twodimensional), and bodies (three-dimensional). Moreover, the fractal geometry has been shown to be an efficient method for studying rock fragmentation [16]. Li et al. [17] discussed the relationship between the fractal characteristics of cracks in the rock and rock burst. They suggested that low fractal characteristics could promote rock burst. Wang et al. [18] found that the fractal dimension of rock fragmentation reflects not only the fracture properties but also the stress state of rock and the loading and unloading paths. Many studies of the fractal characteristics of rock failure have been published (e.g., $[19,20])$. However, few experimental studies have been carried out on the fractal characteristics of rock failure under triaxial unloading confining pressure. For example, $\mathrm{He}$ et al. [21] simulated rock burst caused by excavation under high-stress conditions by unilaterally unloading granite in a 3D stress state. They also analyzed the fractal laws of rock burst fragmentation in detail.

In this study, we analyzed surface cracking and fragmentation of coal and sandstone by adopting fractal theory. To illustrate the effects of the unloading rate and initial unloading confining pressure on the fractal dimension of surface cracking and fragmentation in coal and sandstone under unloading conditions, a series of triaxial unloading confining pressure tests with different unloading rates and initial unloading confining pressures were conducted using an MTS815.02 electrohydraulic servo rock mechanics testing system. We focused on addressing the fractal dimension of surface cracking and fragmentation in coal and sandstone under different conditions of unloading. Our investigation can provide guidelines for evaluating the stability of rock mass and predicting the failure properties of coal and sandstone during underground excavation under high in situ stress conditions. Our results also contribute to the theoretical understanding of the failure response and mechanism of coal and sandstone under high-stress conditions during loading and unloading.

\section{Materials and Methods}

2.1. Sample Selection. The coal and rock samples used in the tests were taken from the No. 3 coal and its sandstone roof in Yangcun Coal Mine, Jining, Shandong, China (Figure 1). The structure of No. 3 coal is relatively simple, with 1-2 layers of the intercalated rock comprising carbonaceous mudstone and pyrite nodules, with a thickness of $0.02-0.44 \mathrm{~m}$. The direct roof of No. 3 coal is composed mainly of sandstone and sandy mudstone, overlain by mudstone, with a general thickness of $0.35-11.36 \mathrm{~m}$.

According to engineering rock mass test standards, the extracted coal block was cut into $50 \times 100 \mathrm{~mm}$ (diameter$\times$ height) cylinders; three samples were prepared for each test run, with a total of 102 samples, including a number of spares. Before testing, the samples were firstly subjected to ultrasonic testing, and the specimens that showed high wave velocities were removed, leaving those specimens with similar velocities, as shown in Table 1.

2.2. Test Program. The tests were carried out using an MTS815.02 electrohydraulic servo rock mechanics test system. The testing system can meet the test requirements under a variety of complex loading and unloading paths. The test plan in this study was the same as that of Yang et al. [5] (see Figure 2). And the testing apparatus and posttest samples are shown in Figure 3.

The results of the triaxial unloading confining pressure tests with different unloading rates and initial unloading confining pressures are shown in Tables 2 and 3 , where $\varepsilon_{1}$ is the axial strain $(\mathrm{MPa}), \varepsilon_{3}$ is the radial strain $(\mathrm{MPa}), \sigma_{3}$ is the initial unloading confining pressure $(\mathrm{MPa}), v_{\sigma 3}$ is the unloading rate $\left(\mathrm{MPa} \cdot \mathrm{s}^{-1}\right), \sigma_{1}-\sigma_{3}$ represents the principal stress difference when the sample is at peak stress ( $\mathrm{MPa})$, and $\sigma_{3}{ }^{\prime}$ is the confining pressure when the sample fails ( $\left.\mathrm{MPa}\right)$.

\section{Fractal Characteristics of Surface Cracks in Coal and Sandstone}

3.1. Calculating the Fractal Dimension. To date, considerable methods have been used for obtaining the fractal dimension such as the Hausdorff dimension, information dimension, and box dimension.

The box dimension, which is adopted in this paper, can be expressed as follows:

$$
D_{s}=-\lim _{r \longrightarrow 0} \frac{\lg N(r)}{\lg (1 / r)},
$$

where $D_{s}$ is the fractal dimension of the surface cracks, $r$ is the size of a box covering the fractal figures $(\mathrm{m})$, and $N(r)$ is the number of boxes. In practical applications, because $r$ is finite, the scaling rule between $N(r)$ and $r$ needs to be determined. The box dimension method can be used in both simple and complex cases.

3.2. Obtaining the Surface Crack Image. To obtain an image of the surface cracks in the rock samples after the triaxial unloading confining pressure tests, a transparent film paper was attached to the surface of the rock sample and the outline of the surface cracks was traced with an oil marker pen, as shown in Figure 4. Then, the surface crack sketch was scanned and converted into a digital image (Figure 5).

3.3. Fractal Characteristics of the Surface Cracks. The $D_{s}$ curve for the tested sample calculated by the box dimension method is illustrated in Figure 6. The slope of the curve represents the fractal dimension. The correlation coefficient of the fitting curve $\lg N(r)-\lg (1 / r)$ is about 0.94 , which indicates that the surface cracks of the failed sample have fractal characteristics.

$D_{s}$ in the coal and sandstone samples under different unloading conditions is shown in Table 4.

From Figure 7, it can be seen that, at the same unloading rate, $D_{s}$ in the coal and sandstone samples decreased with 


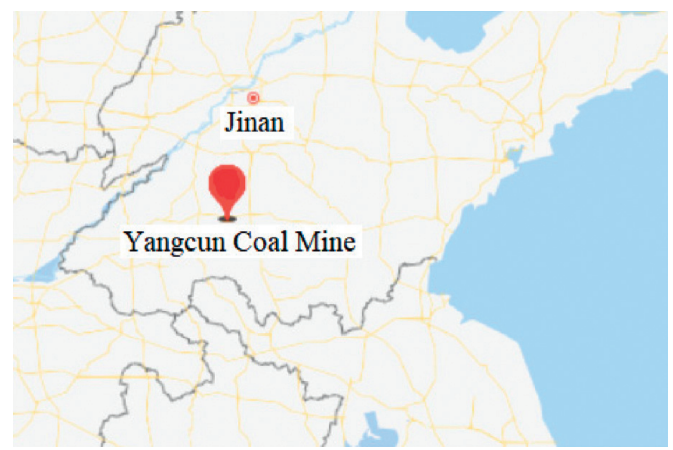

(a)

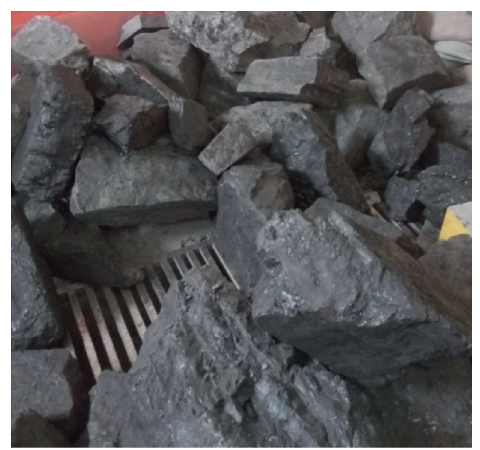

(b)
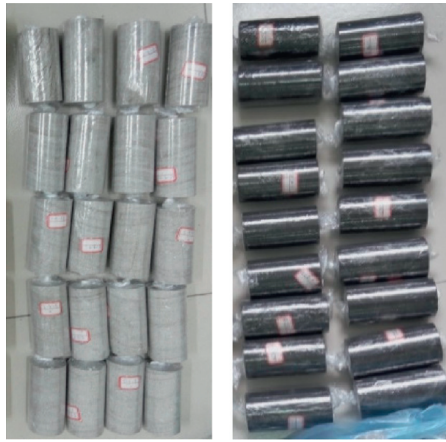

(c)

Figure 1: (a) Coal mine location, (b) rock samples, and (c) prepared test specimens.

TABLE 1: Acoustic wave test results of typical rock specimens.

\begin{tabular}{|c|c|c|c|}
\hline Lithology & Number & $P$-wave velocity $(\mathrm{m} / \mathrm{s})$ & $S$-wave velocity $(\mathrm{m} / \mathrm{s})$ \\
\hline \multirow{11}{*}{ Coal } & $16-\mathrm{N}-18$ & 1932.746 & 1005.961 \\
\hline & $16-\mathrm{N}-17$ & 1990.223 & 1192.537 \\
\hline & $16-\mathrm{M}-17$ & 1946.301 & 1072.167 \\
\hline & $16-\mathrm{M}-19$ & 1972.257 & 1153.173 \\
\hline & $16-\mathrm{M}-10$ & 1988.963 & 1014.426 \\
\hline & $16-\mathrm{M}-14$ & 1944.138 & 1051.107 \\
\hline & $16-\mathrm{N}-16$ & 1896.321 & 1062.36 \\
\hline & $16-\mathrm{N}-20$ & 1957.746 & 1051.003 \\
\hline & $16-\mathrm{N}-9$ & 1919.274 & 1134.921 \\
\hline & $16-1-8$ & 1981.991 & 975.2184 \\
\hline & $16-1-1$ & 1942.238 & 948.1264 \\
\hline \multirow{11}{*}{ Sandstone } & S-7-5 & 4891.536 & 2234.588 \\
\hline & S-7-1 & 5021.928 & 3076.94 \\
\hline & $S-7-3$ & 4828.032 & 2559.21 \\
\hline & S-2-6 & 5214.408 & 2908.235 \\
\hline & $S-2-11$ & 4990.176 & 2664.642 \\
\hline & S-5-2 & 5239.656 & 2856.324 \\
\hline & S-2-4 & 5418.984 & 2895.125 \\
\hline & $S-2-10$ & 5296.032 & 3008.285 \\
\hline & $S-1-5$ & 5060.28 & 3095.432 \\
\hline & S-5-6 & 5173.08 & 2682.26 \\
\hline & $S-5-13$ & 4856.928 & 2458.953 \\
\hline
\end{tabular}

the initial unloading confining pressure (Figure 7(a)). This indicates that when the initial confining pressure is relatively low, the samples undergo splitting and shear failure; when the initial confining pressure is higher, the samples are mainly in shear failure. The shear failure of the samples is more obvious when the rock is under a higher confining pressure. The relationship between $D_{s}$ in the coal and sandstone samples and the initial unloading confining pressure can be expressed by two linear equations as follows:

$$
\begin{aligned}
D_{\text {Coal.s }} & =-0.00305 \sigma_{3}+1.0907, \quad R^{2}=0.865, \\
D_{\text {Sandstone.s }}=-0.01031 \sigma_{3}+1.0952, & R^{2}=0.862,
\end{aligned}
$$

where $D_{\text {Coal.s }}$ represents $D_{s}$ of the coal samples and $D_{\text {Sandstone.s }}$ represents $D_{s}$ of the sandstone samples.

In Figure $7(\mathrm{~b})$, at the same initial unloading confining pressure, $D_{s}$ in the coal and sandstone increases with the unloading rate. This is because when the unloading rate is

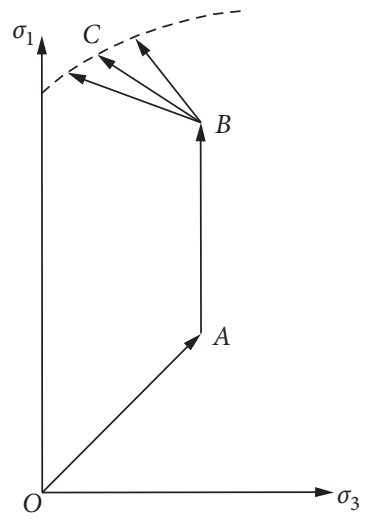

FIGURE 2: Stress path of the unloading confining pressure.

relatively high, the failure of the sample is accelerated, and the stored energy in the sample cannot be expended in time, which results in rapid energy release when the sample fails. 


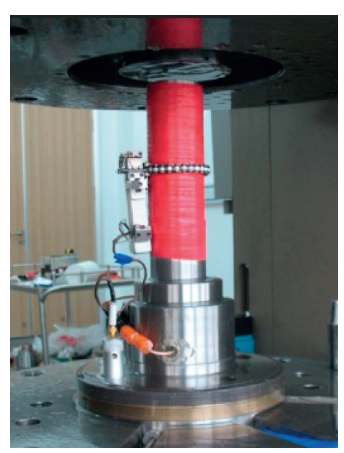

(a)

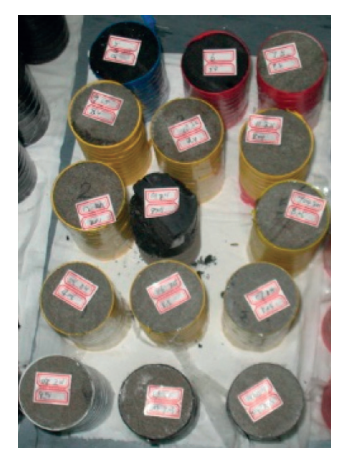

(b)
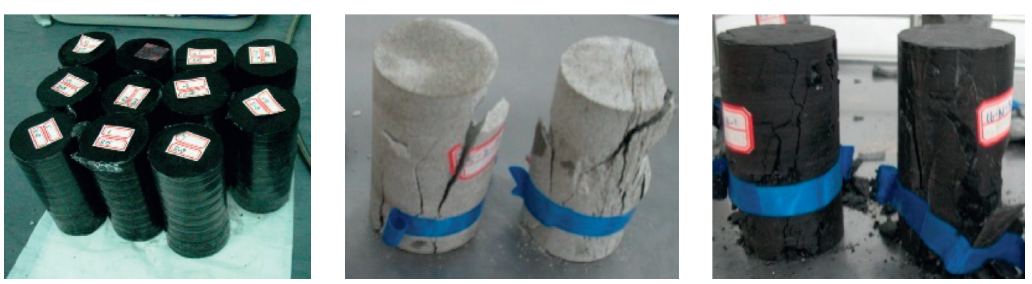

(c) (d)

Figure 3: Testing apparatus and rock samples after testing.

TABLE 2: Results of conventional triaxial compression tests.

\begin{tabular}{lcc}
\hline Lithology & $\sigma_{3}(\mathrm{MPa})$ & $\sigma_{1}-\sigma_{3}(\mathrm{MPa})$ \\
\hline \multirow{3}{*}{ Coal } & 4 & 33.19 \\
& 7 & 39.21 \\
& 10 & 50.34 \\
\hline \multirow{3}{*}{ Sandstone } & 4 & 144.36 \\
& 7 & 153.19 \\
& 10 & 158.43 \\
& 13 & 166.33 \\
& 16 & 176.49 \\
& 19 & 189.86 \\
\hline
\end{tabular}

TABLE 3: Results of triaxial unloading confining pressure tests.

\begin{tabular}{ccccc}
\hline Lithology & $\sigma_{3}(\mathrm{MPa})$ & $v_{\sigma 3}(\mathrm{MPa} / \mathrm{s})$ & $\sigma_{1}-\sigma_{3}(\mathrm{MPa})$ & $\sigma_{3}^{\prime}(\mathrm{MPa})$ \\
\hline \multirow{6}{*}{ Coal } & 4 & 0.02 & 31.74 & 2.30 \\
& 4 & 0.05 & 30.02 & 0.63 \\
& 4 & 0.08 & 26.99 & 0.61 \\
& 7 & 0.02 & 37.23 & 4.39 \\
& 7 & 0.05 & 36.04 & 3.84 \\
& 10 & 0.08 & 36.26 & 1.63 \\
& 10 & 0.02 & 52.06 & 6.13 \\
& 10 & 0.05 & 50.21 & 4.58 \\
& 10 & 0.11 & 44.44 & 4.58 \\
& 10 & 0.14 & 45.42 & 1.57 \\
& 4 & 0.02 & 135.27 & 1.40 \\
\hline \multirow{5}{*}{ Sandstone } & 4 & 0.05 & 132.95 & 0.01 \\
& 4 & 0.08 & 124.01 & 0.01 \\
& 7 & 0.02 & 138.89 & 4.36 \\
& 7 & 0.05 & 136.36 & 1.88 \\
& 10 & 0.08 & 125.75 & 0.00 \\
& 10 & 0.02 & 151.60 & 7.25 \\
& 10 & 0.05 & 141.05 & 4.99 \\
& 10 & 0.08 & 138.63 & 2.75 \\
& 10 & 0.14 & 132.77 & 2.70 \\
& 13 & 0.05 & 132.21 & 0.00 \\
& 16 & 0.05 & 149.93 & 6.82 \\
& 19 & 0.05 & 189.42 & 8.69 \\
& & & & 11.56 \\
\hline
\end{tabular}

In this respect, the failure form of the rock sample under high unloading rate is similar to that under uniaxial compression. The relationships between $D_{s}$ in the coal and sandstone samples and the unloading rate can also be expressed in the form of linear equations as

$$
\begin{aligned}
D_{\text {Coal. } . s} & =0.26433 v_{\sigma_{3}}+1.0409, \quad R^{2}=0.880, \\
D_{\text {Sandstone.s }} & =-1.0906 v_{\sigma_{3}}+0.9251, \quad R^{2}=0.878 .
\end{aligned}
$$

Equations (2)-(5) suggest that the surface cracks of different lithologies show different fractal characteristics. Moreover, the fractal dimension of the surface cracks in coal is higher than that in sandstone. For example, when the initial unloading confining pressure is $7 \mathrm{MPa}$ and the unloading rate is $0.05 \mathrm{MPa} / \mathrm{s}$, the $D_{s}$ values in the coal and sandstone samples are 1.07 and 1.03 , respectively. Thus, the lithology has a notable effect on the fractal characteristics of the surface cracks, and a rock sample with more internal fissures presents more surface cracks when the sample fails compared with a sample with less fissures under the same unloading conditions.

\section{Fractal Characteristics of Fragmentation in Coal and Sandstone}

4.1. Calculating the Fractal Dimension. The fractal dimension of the fragmentation can be calculated by the following method.

Assuming the mass of the rock fragments follows the Weibull distribution, we can use the following equation based on Weibull statistics:

$$
\frac{M(r)}{M_{0}}=1-\exp \left[-\left(\begin{array}{c}
r \\
\varepsilon
\end{array}\right)^{k}\right],
$$

where $M(r)$ is the mass of the fragments that are smaller than $r(\mathrm{~kg}), M_{0}$ is the total mass of all the rock fragments within the scale criterion $(\mathrm{kg}), \varepsilon$ is a parameter related to the average size of the rock fragments, and $k$ is the slope of the fitted logarithmic curve. Based on equation (6), we obtain

$$
\frac{M(r)}{M_{0}}=\frac{r^{k}}{\varepsilon} \text {. }
$$

To describe $D_{f}$, the fractal dimension of fragmentation in coal and sandstone, we derive 


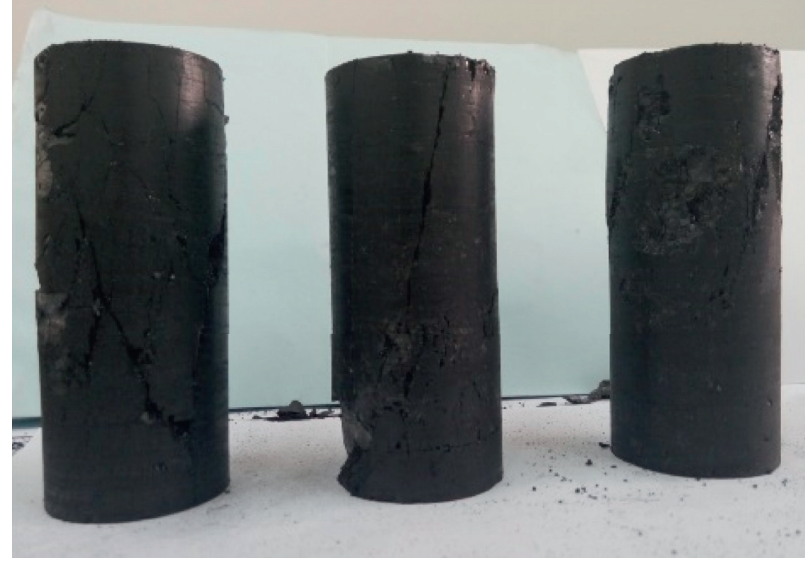

(a)

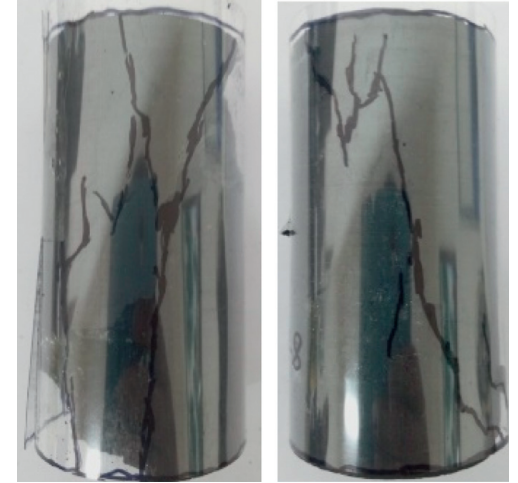

(b)

FIGURE 4: Rock samples with surface cracks after tests.

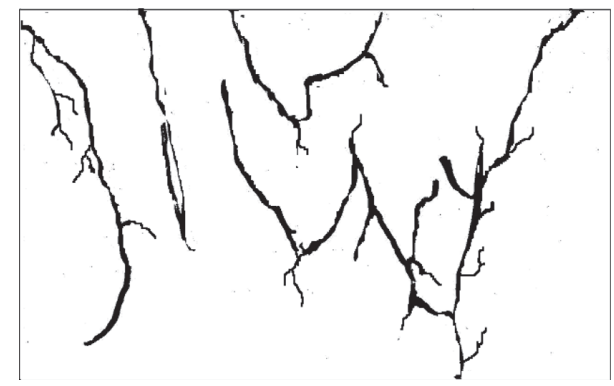

FIGURE 5: Distribution of surface cracks in the failed rock sample.

$$
D_{f}=3-k
$$

The values of $M(r)$ and $M_{0}$ were obtained by sieving the fragments and calculating the value of $k$. In this study, we set a fragmentation threshold of $19 \mathrm{~mm}$ when calculating $D_{f}$. Thus, only fragments smaller than $19 \mathrm{~mm}$ were used for the calculation, while the effect of the larger fragments on the fractal dimension was neglected. The sieved fragments of the coal and sandstone samples are shown in Figures 8 and 9, respectively.

4.2. Fractal Characteristics of Fragmentation. The mass fractions of the fragments for the different fragment scales derived from the coal and sandstone samples under different unloading conditions are shown in Tables 5-7. The $\lg r-$ $\lg \left(M(r) / M_{0}\right)$ logarithmic curves under different unloading conditions are shown in Figures 10 and 11. The results of the fitting slopes of the logarithmic curves and $D_{f}$ are shown in Tables 8 and 9. Figure 12 shows the effects of the unloading condition on $D_{f}$.

Figure 12(a) shows that, at the same unloading rate, $D_{f}$ in the coal and sandstone samples decreases as the initial unloading confining pressure increases. This can be explained as follows: when the initial confining pressure is relatively high, the samples are mainly in shear failure, which results in a higher number of larger fragments in the

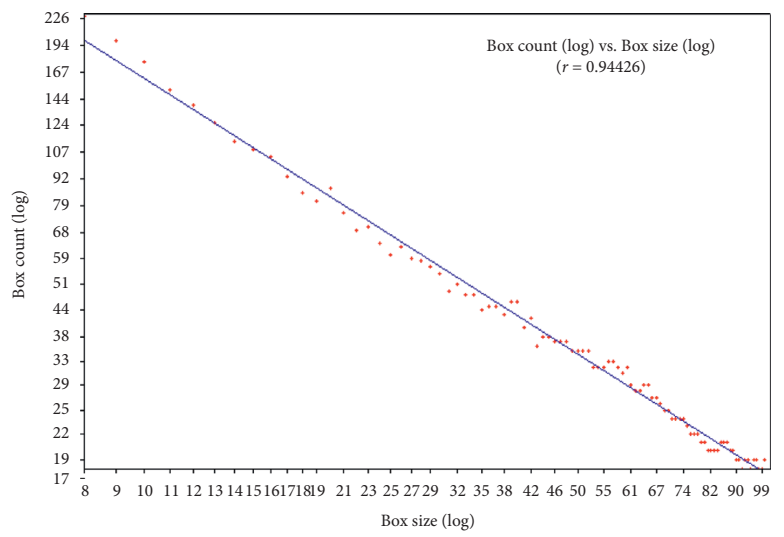

FIGURE 6: Fractal dimension curve calculated by the box dimension method for surface cracks of the failed sample.

rock when the sample fails. In other words, the fragmentation of the samples is less homogeneous when the initial confining pressure is higher. Here also, the relationship between $D_{f}$ in the coal and sandstone samples and the initial unloading confining pressure can be expressed by two linear equations:

$$
\begin{aligned}
D_{\text {Coal. } f} & =-0.037 \sigma_{3}+2.76, \quad R^{2}=0.97, \\
D_{\text {Sandstone. } f} & =-0.023 \sigma_{3}+2.58, \quad R^{2}=0.98,
\end{aligned}
$$

where $D_{\text {Coal. } f}$ represents $D_{f}$ in coal and $D_{\text {Sandstone. } f}$ represents $D_{f}$ in sandstone.

Under the same initial unloading confining pressure, $D_{f}$ in the coal and sandstone samples decreases with the increasing unloading rate (Figure $12(\mathrm{~b})$ ). Thus, the degree of fragmentation of the sample has a positive correlation with the unloading rate, and the inhomogeneity of the fragmentation in the coal and sandstone samples has the same trend. Moreover, the relationship between $D_{f}$ in the coal and sandstone samples and the unloading rate can be expressed by two additional linear equations, as follows: 
TABLE 4: Fractal dimensions of surface cracks with different unloading conditions.

\begin{tabular}{|c|c|c|c|c|c|}
\hline Lithology & $\sigma_{3}(\mathrm{MPa})$ & $v_{\sigma}(\mathrm{MPa} / \mathrm{s})$ & $\sigma_{1}-\sigma_{3}(\mathrm{MPa})$ & Fractal dimension & Correlation coefficient \\
\hline \multirow{11}{*}{ Coal } & 4 & 0.02 & 30.82 & 1.0605 & 0.9427 \\
\hline & 4 & 0.05 & 29.15 & 1.077 & 0.9562 \\
\hline & 4 & 0.08 & 26.20 & 1.0981 & 0.9631 \\
\hline & 7 & 0.02 & 36.15 & 1.0624 & 0.9554 \\
\hline & 7 & 0.05 & 34.99 & 1.0726 & 0.9231 \\
\hline & 7 & 0.08 & 35.20 & 1.0774 & 0.9635 \\
\hline & 10 & 0.02 & 50.54 & 1.044 & 0.9523 \\
\hline & 10 & 0.05 & 48.75 & 1.0587 & 0.9442 \\
\hline & 10 & 0.08 & 43.15 & 1.058 & 0.9522 \\
\hline & 10 & 0.11 & 44.10 & 1.074 & 0.9633 \\
\hline & 10 & 0.14 & 42.24 & 1.076 & 0.9325 \\
\hline \multirow{14}{*}{ Sandstone } & 4 & 0.02 & 131.33 & 1.024 & 0.0952 \\
\hline & 4 & 0.05 & 129.08 & 1.034 & 0.9421 \\
\hline & 4 & 0.08 & 120.40 & 1.059 & 0.9365 \\
\hline & 7 & 0.02 & 134.84 & 0.9976 & 0.9365 \\
\hline & 7 & 0.05 & 132.39 & 1.019 & 0.9521 \\
\hline & 7 & 0.08 & 122.09 & 1.0621 & 0.9456 \\
\hline & 10 & 0.02 & 147.18 & 0.9206 & 0.9471 \\
\hline & 10 & 0.05 & 136.94 & 1.0108 & 0.9369 \\
\hline & 10 & 0.08 & 134.59 & 1.014 & 0.9354 \\
\hline & 10 & 0.11 & 128.90 & 1.054 & 0.9512 \\
\hline & 10 & 0.14 & 128.36 & 1.0626 & 0.9432 \\
\hline & 13 & 0.05 & 145.56 & 0.9875 & 0.9366 \\
\hline & 16 & 0.05 & 154.78 & 0.9371 & 0.9412 \\
\hline & 19 & 0.05 & 175.70 & 0.8712 & 0.9356 \\
\hline
\end{tabular}

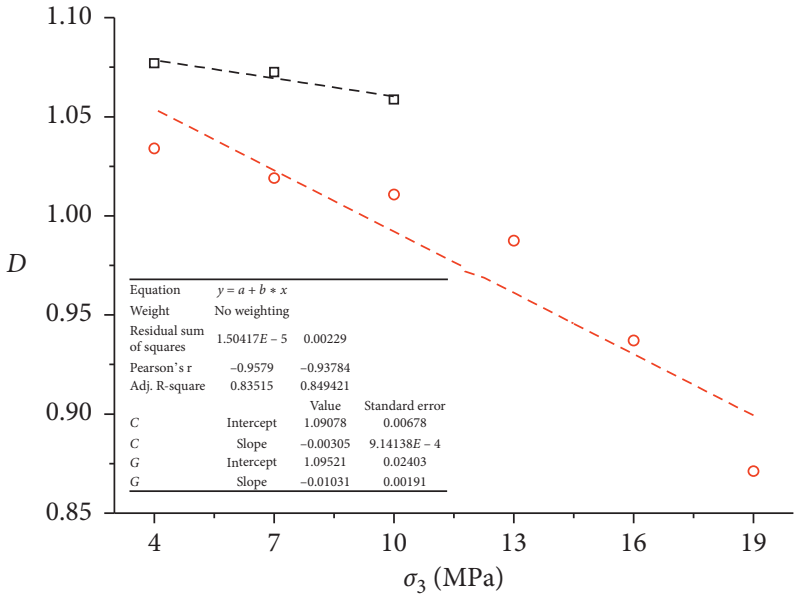

口 Coal

- Sandstone

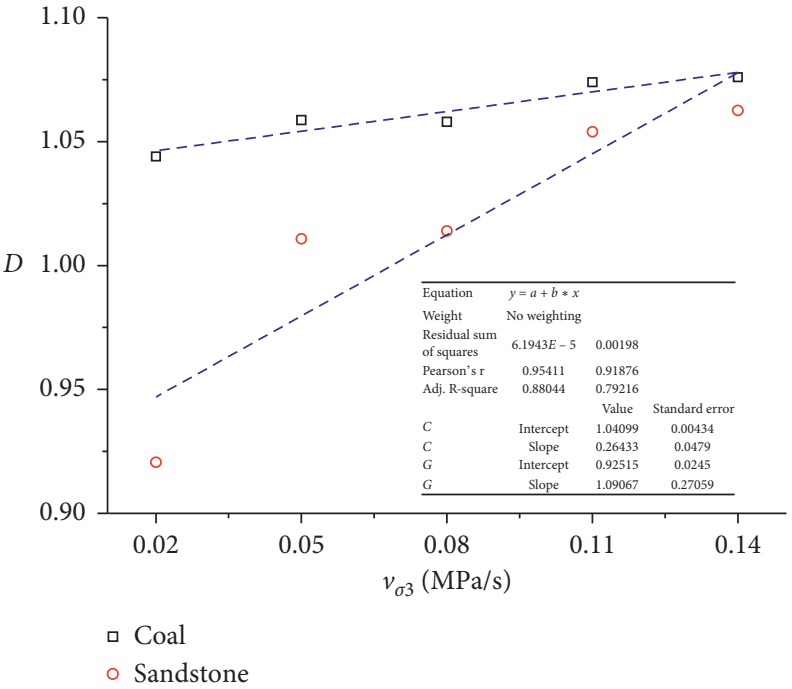

(b)

(a)

FIGURE 7: Effects of the unloading conditions on the fractal dimension of surface cracks. (a) Fractal dimension with different initial unloading confining pressures. (b) Fractal dimension with different unloading rates.

$$
\begin{aligned}
D_{\text {Coal. } f} & =-1.545 v_{\sigma_{3}}+2.48, \quad R^{2}=0.90, \\
D_{\text {Sandstone. } f} & =-1.464 v_{\sigma_{3}}+2.44, \quad R^{2}=0.98 .
\end{aligned}
$$

Equations (9)-(12) indicate that the fragmentation of different lithologies shows different fractal characteristics. Moreover, the fractal dimension of the surface cracks in the coal samples is higher than that in the sandstone 


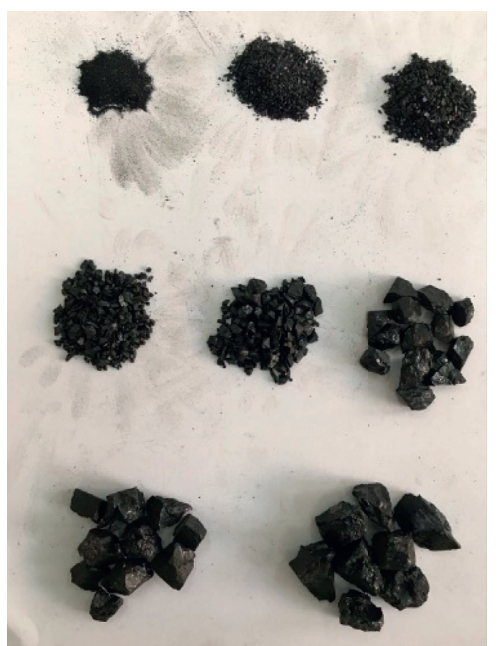

(a)

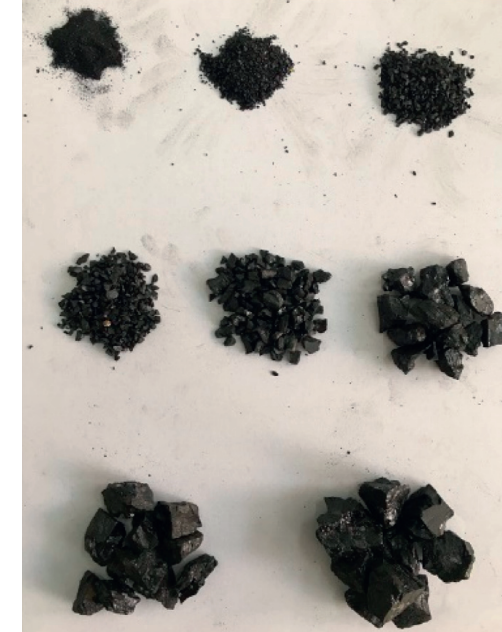

(b)

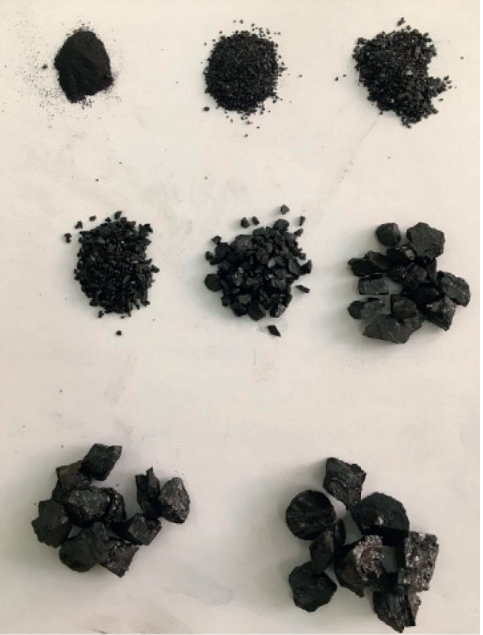

(c)

Figure 8: Sieving results of fragmentation in coal. (a) $4 \mathrm{MPa}$. (b) $7 \mathrm{MPa}$. (c) $10 \mathrm{MPa}$.

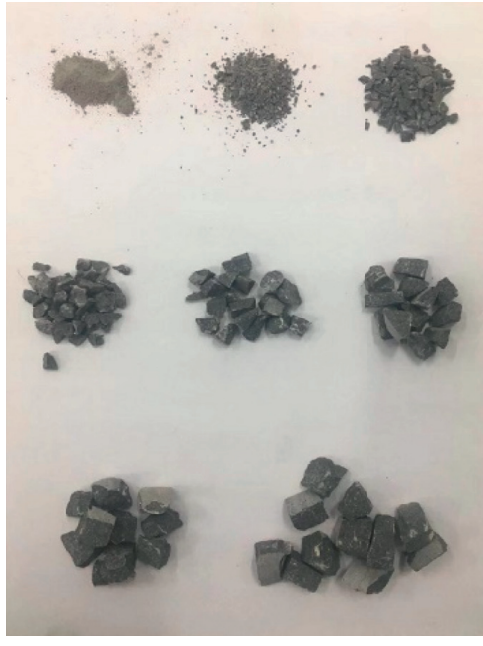

(a)

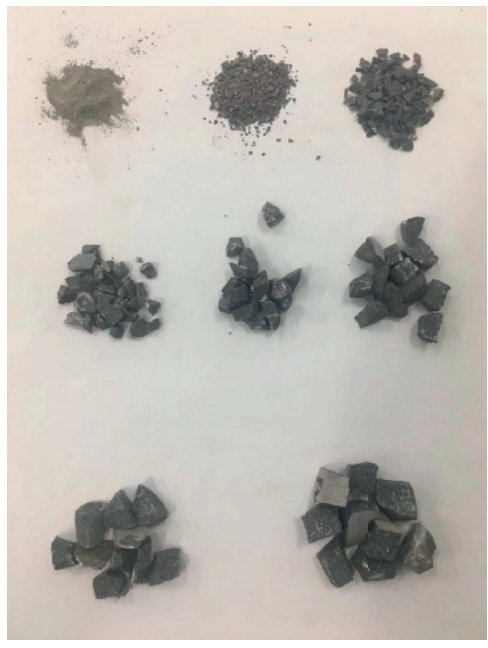

(b)

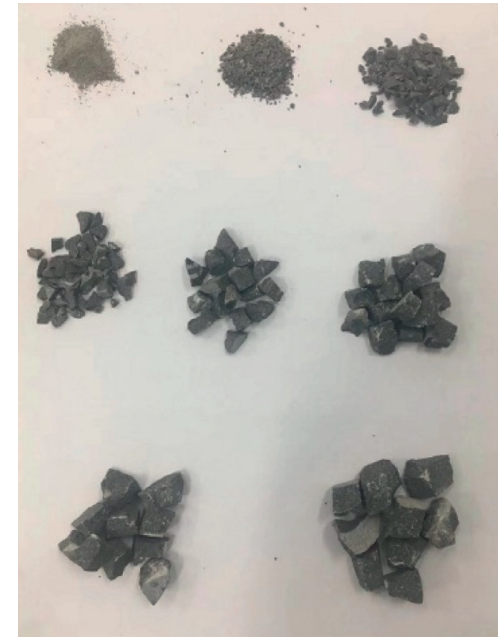

(c)

Figure 9: Sieving results of fragmentation in sandstone. (a) $4 \mathrm{MPa}$. (b) $7 \mathrm{MPa}$. (c) $10 \mathrm{MPa}$.

TABLE 5: Mass fractions of fragments at different scales in coal and sandstone samples under different initial unloading confining pressures.

\begin{tabular}{|c|c|c|c|c|c|c|c|c|c|}
\hline \multirow{3}{*}{ Scale (mm) } & \multicolumn{9}{|c|}{ Confining pressure (MPa) } \\
\hline & \multicolumn{3}{|c|}{ Coal } & \multicolumn{6}{|c|}{ Sandstone } \\
\hline & 4 & 7 & 10 & 4 & 7 & 10 & 13 & 16 & 19 \\
\hline $0.3 \geq d$ & 0.030 & 0.023 & 0.015 & 0.023 & 0.017 & 0.013 & 0.010 & 0.007 & 0.005 \\
\hline $0.6 \geq d>0.3$ & 0.059 & 0.050 & 0.044 & 0.054 & 0.045 & 0.039 & 0.037 & 0.028 & 0.032 \\
\hline $1.18 \geq d>0.6$ & 0.100 & 0.083 & 0.061 & 0.076 & 0.068 & 0.063 & 0.046 & 0.050 & 0.041 \\
\hline $2.36 \geq d>1.18$ & 0.139 & 0.127 & 0.088 & 0.116 & 0.105 & 0.097 & 0.090 & 0.094 & 0.089 \\
\hline $4.75 \geq d>2.36$ & 0.151 & 0.155 & 0.142 & 0.147 & 0.133 & 0.156 & 0.143 & 0.148 & 0.141 \\
\hline $9.5 \geq d>4.75$ & 0.162 & 0.176 & 0.181 & 0.163 & 0.185 & 0.171 & 0.179 & 0.171 & 0.161 \\
\hline $13.2 \geq d>9.5$ & 0.170 & 0.179 & 0.219 & 0.190 & 0.206 & 0.198 & 0.196 & 0.201 & 0.194 \\
\hline $19 \geq d>13.2$ & 0.190 & 0.207 & 0.251 & 0.232 & 0.242 & 0.263 & 0.300 & 0.301 & 0.337 \\
\hline
\end{tabular}


TABLE 6: Mass fractions of fragments at different scales in the coal sample under different unloading rates.

\begin{tabular}{|c|c|c|c|c|c|}
\hline \multirow{3}{*}{ Scale $(\mathrm{mm})$} & \multicolumn{5}{|c|}{ Unloading rate $(\mathrm{MPa} / \mathrm{s})$} \\
\hline & & & Coal & & \\
\hline & 0.02 & 0.05 & 0.08 & 0.11 & 0.14 \\
\hline $0.3 \geq d$ & 0.0219 & 0.0152 & 0.0154 & 0.0134 & 0.0097 \\
\hline $0.6 \geq d>0.3$ & 0.0523 & 0.0436 & 0.0342 & 0.0335 & 0.0327 \\
\hline $1.18 \geq d>0.6$ & 0.0717 & 0.0609 & 0.0544 & 0.0570 & 0.0570 \\
\hline $2.36 \geq d>1.18$ & 0.1029 & 0.0882 & 0.1017 & 0.0950 & 0.0970 \\
\hline $4.75 \geq d>2.36$ & 0.1408 & 0.1420 & 0.1228 & 0.1229 & 0.1248 \\
\hline $9.5 \geq d>4.75$ & 0.1703 & 0.1805 & 0.1671 & 0.1687 & 0.1673 \\
\hline $13.2 \geq d>9.5$ & 0.1956 & 0.2191 & 0.2255 & 0.2291 & 0.2267 \\
\hline $19 \geq d>13.2$ & 0.2445 & 0.2505 & 0.2789 & 0.2804 & 0.2848 \\
\hline
\end{tabular}

TABLe 7: Mass fractions of fragments at different scales in the sandstone sample under different unloading rates.

\begin{tabular}{|c|c|c|c|c|c|}
\hline \multirow{3}{*}{ Scale (mm) } & \multicolumn{5}{|c|}{ Unloading rate $(\mathrm{MPa} / \mathrm{s})$} \\
\hline & \multicolumn{5}{|c|}{ Sandstone } \\
\hline & 0.02 & 0.05 & 0.08 & 0.11 & 0.14 \\
\hline $0.3 \geq d$ & 0.0219 & 0.0152 & 0.0154 & 0.0134 & 0.0097 \\
\hline $0.6 \geq d>0.3$ & 0.0523 & 0.0436 & 0.0342 & 0.0335 & 0.0327 \\
\hline $1.18 \geq d>0.6$ & 0.0717 & 0.0609 & 0.0544 & 0.0570 & 0.0570 \\
\hline $2.36 \geq d>1.18$ & 0.1029 & 0.0882 & 0.1017 & 0.0950 & 0.0970 \\
\hline $4.75 \geq d>2.36$ & 0.1408 & 0.1420 & 0.1228 & 0.1229 & 0.1248 \\
\hline $9.5 \geq d>4.75$ & 0.1703 & 0.1805 & 0.1671 & 0.1687 & 0.1673 \\
\hline $13.2 \geq d>9.5$ & 0.1956 & 0.2191 & 0.2255 & 0.2291 & 0.2267 \\
\hline $19 \geq d>13.2$ & 0.2445 & 0.2505 & 0.2789 & 0.2804 & 0.2848 \\
\hline
\end{tabular}

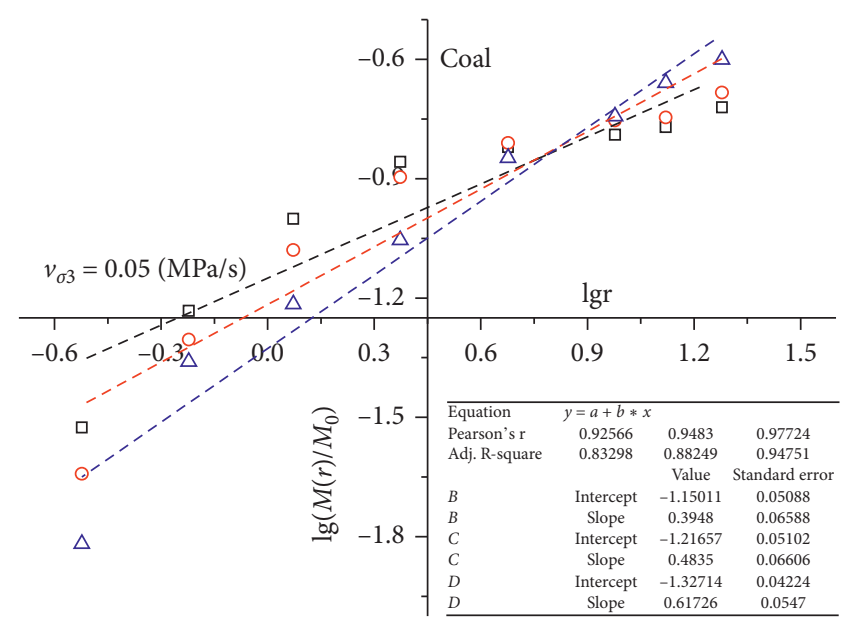

ㄷ $4 \mathrm{MPa}$

- $7 \mathrm{MPa}$

$\triangle 10 \mathrm{MPa}$

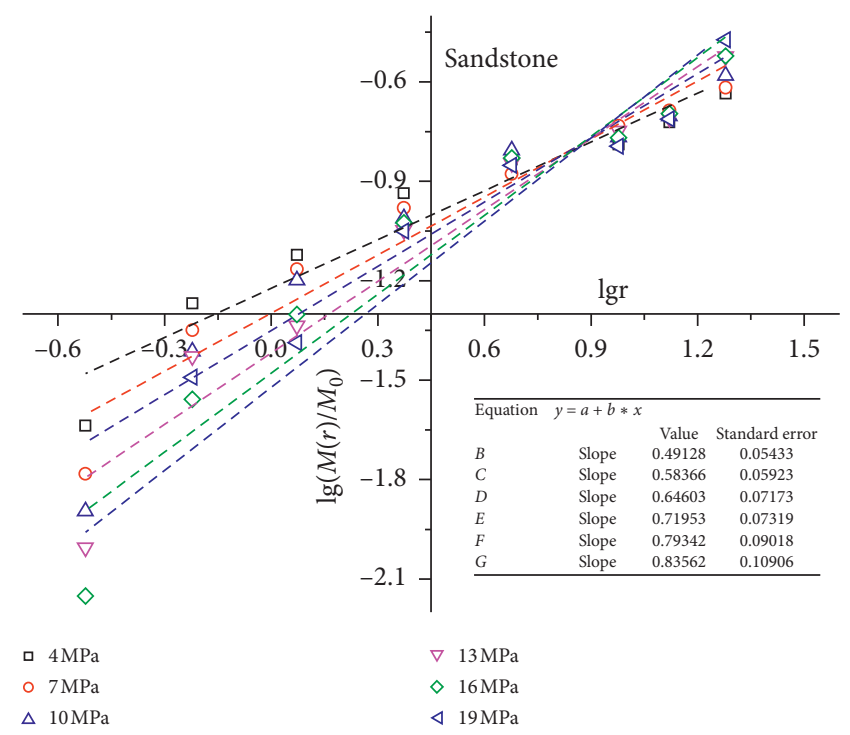

(b)

FIGURE 10: Logarithmic curves under different initial unloading confining pressures. (a) Coal. (b) Sandstone.

samples. For example, when the initial unloading confining pressure is $7 \mathrm{MPa}$ and the unloading rate is $0.05 \mathrm{MPa} / \mathrm{s}$, the $D_{f}$ values in the coal and sandstone samples are 2.51 and 2.41, respectively. Thus, the lithology has a notable effect on the fractal characteristics of the rock fragmentation; rock samples with more internal fissures have a higher degree of fragmentation and less homogeneous fragments when the sample fails compared with samples with less fissures under the same unloading conditions. 


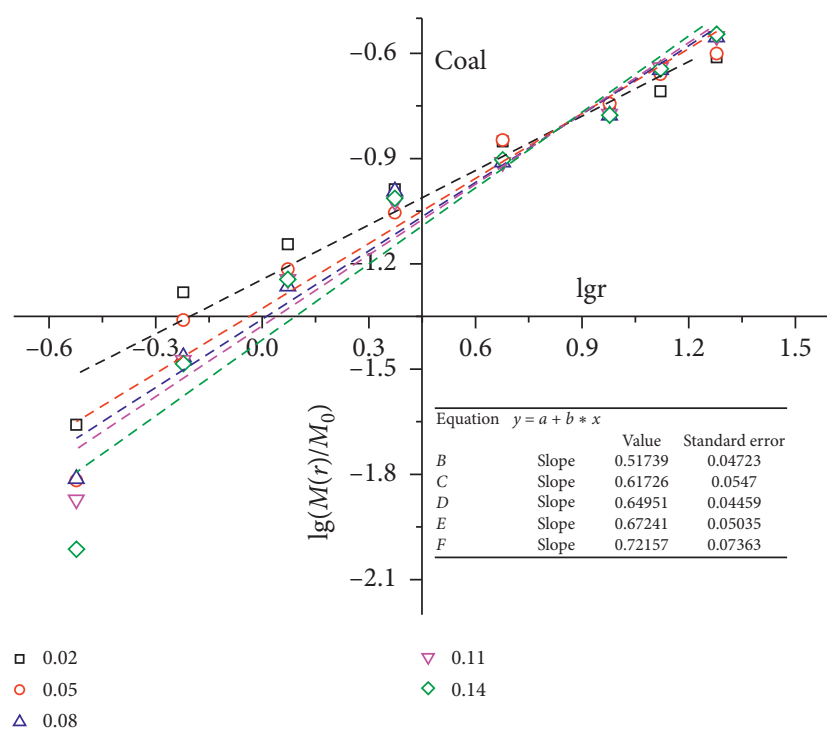

(a)

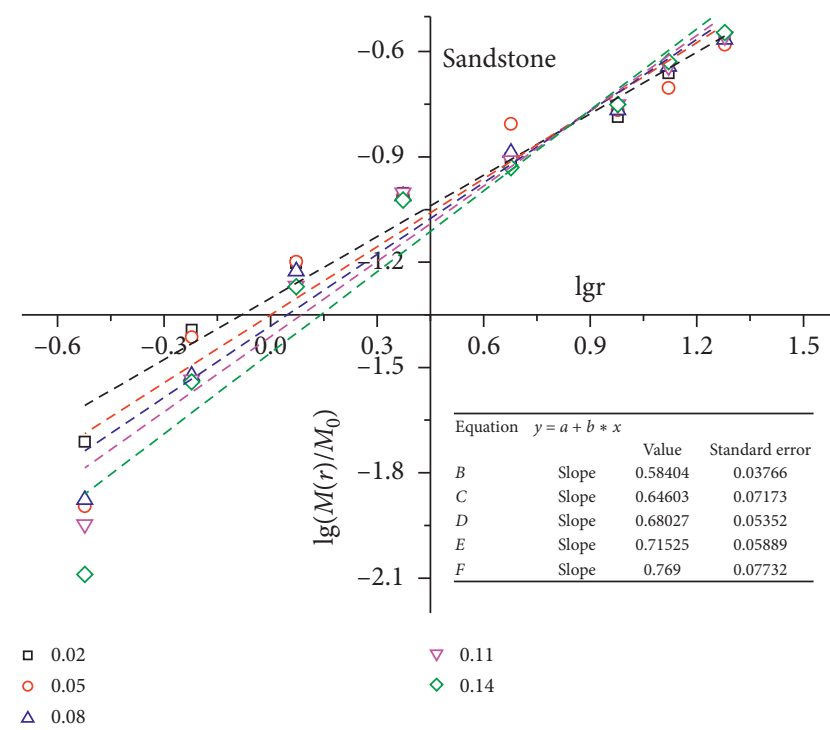

(b)

Figure 11: Logarithmic curves under different unloading rates. (a) Coal. (b) Sandstone.

TABLE 8: Fractal dimension of fragmentation under different initial unloading confining pressures.

\begin{tabular}{|c|c|c|c|c|}
\hline \multirow{2}{*}{ Initial unloading confining pressure $(\mathrm{MPa})$} & \multicolumn{2}{|c|}{ Coal } & \multicolumn{2}{|c|}{ Sandstone } \\
\hline & $k$ & $D$ & $k$ & $D$ \\
\hline 4 & 0.3948 & 2.6052 & 0.4913 & 2.5087 \\
\hline 7 & 0.4835 & 2.5165 & 0.5837 & 2.4163 \\
\hline 10 & 0.6172 & 2.3828 & 0.646 & 2.354 \\
\hline 13 & - & - & 0.7195 & 2.2805 \\
\hline 16 & - & - & 0.7934 & 2.2066 \\
\hline 19 & - & - & 0.8356 & 2.1644 \\
\hline
\end{tabular}

TABLE 9: Fractal dimension of fragmentation under different unloading rates.

\begin{tabular}{lcccc}
\hline Unloading rate $(\mathrm{MPa} / \mathrm{s})$ & \multicolumn{2}{c}{ Coal } & \multicolumn{2}{c}{ Sandstone } \\
& $k$ & $D$ & 0.584 & 2.416 \\
0.02 & 0.5174 & 2.4826 & 0.646 & 2.354 \\
0.05 & 0.6172 & 2.3828 & 0.6803 & 2.3197 \\
0.08 & 0.6495 & 2.3505 & 0.7152 & 2.2848 \\
0.11 & 0.6724 & 2.3276 & 0.769 & 2.231 \\
0.14 & 0.7216 & 2.2784 & & \\
\hline
\end{tabular}

\section{Conclusions}

A series of triaxial unloading confining pressure tests with different unloading rates and initial unloading confining pressures were conducted in this study. The following conclusion were drawn:

(1) At the same unloading rate, the fractal dimension of the surface cracks in coal and sandstone decreased with higher initial unloading confining pressures. When the initial confining pressure was relatively low, the samples underwent splitting and shear failure; when the initial confining pressure was higher, the samples presented mainly shear failure.

(2) Under the same initial unloading confining pressure, the fractal dimension of the surface cracks in the coal and sandstone samples increased as the unloading rate increased. The failure form of the rock samples under high unloading rate was similar to that under uniaxial compression. 


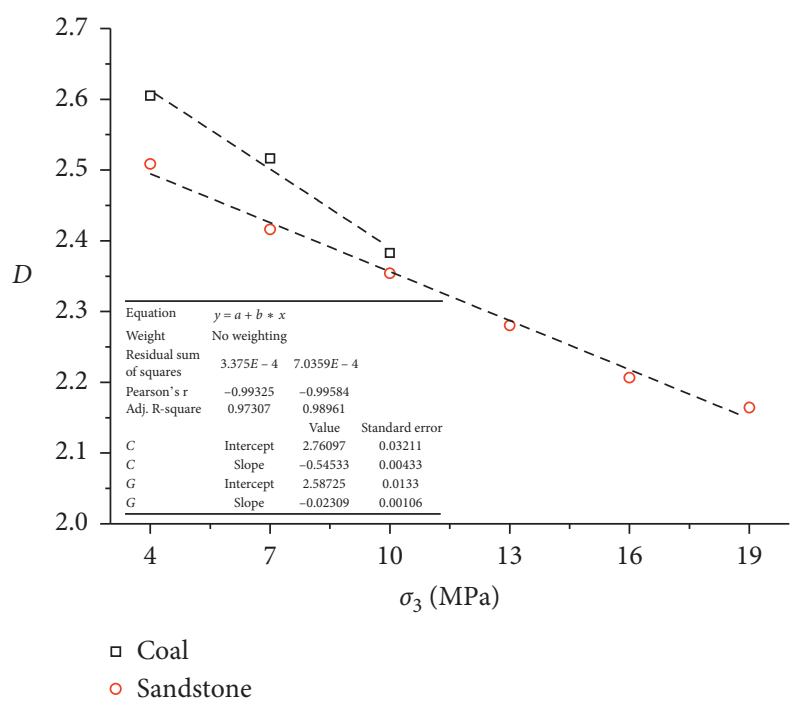

(a)

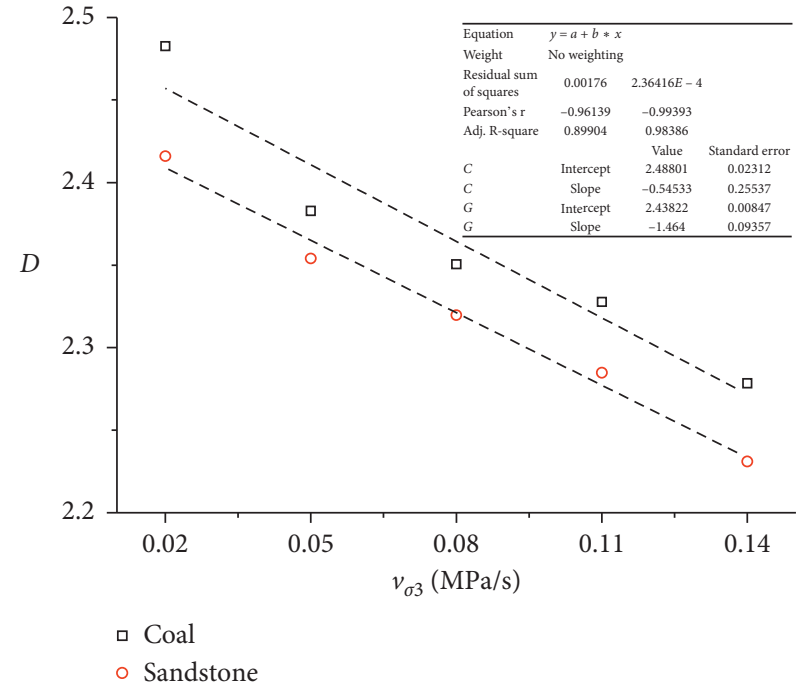

(b)

Figure 12: Effects of unloading conditions on the fractal dimension of fragmentation. (a) Fractal dimension with different initial unloading confining pressures. (b) Fractal dimension with different unloading rates.

(3) At the same unloading rate, the fractal dimension of fragmentation in the coal and sandstone samples decreased with rising initial unloading confining pressure. When the initial confining pressure was higher, the rock presented larger fragments and the fragmentation of the samples was less homogeneous when the sample failed.

(4) Under the same initial unloading confining pressure, the fractal dimension of fragmentation in the coal and sandstone samples decreased with the increasing unloading rate. The degree of fragmentation of the samples and the inhomogeneity of fragmentation in the coal and sandstone samples had a positive correlation with the unloading rate.

(5) The rock lithology had a notable effect on the fractal dimension of the surface cracks and the fragmentation in the coal and sandstone samples. Samples with more internal fissures had more surface cracks and less homogeneous fragments when the sample failed under the same unloading conditions.

\section{Data Availability}

The data used to support the findings of this study are available from the corresponding author upon request.

\section{Conflicts of Interest}

The authors declare that they have no conflicts of interest.

\section{Acknowledgments}

This study was supported by the National Key R\&D Program of China (2018YFC0604705), the National Natural Science Foundation of China (51574156), the Shandong Province Higher Educational Science and Technology Program
(J18KA195), the National Science and Technology Major (2016ZX05043), the Jiangsu Natural Science Foundation (BK20180636), the Advance Research Program (LTKY201803), and Open Funding (MDPC201907).

\section{References}

[1] R. Q. Huang and D. Huang, "Experimental research on mechanical properties of granites unloading condition," Chinese Journal of Rock Mechanics and Engineering, vol. 27, no. 11, pp. 2205-2213, 2008.

[2] R. Q. Huang and D. Huang, "Experimental research on affection laws of unloading rates on mechanical properties of Jinping marble under high geostress," Chinese Journal of Rock Mechanics and Engineering, vol. 29, no. 1, pp. 21-33, 2010.

[3] H. Jin, W. Nie, Y. Zhang et al., "Development of environmental friendly dust suppressant based on the modification of soybean protein isolate," Processes, vol. 7, no. 3, p. 165, 2019.

[4] X. C. Li, B. Bai, L. Z. Tang, and Q. Guo, "Triaxial tests of coal under low and high confining pressures and its plastic characteristics description," Rock and Soil Mechanics, vol. 31, no. 3, pp. 677-682, 2010.

[5] R. Yang, D. Ma, and Y. Yang, "Experimental investigation of energy evolution in sandstone failure during triaxial unloading confining pressure tests," Advances in Civil Engineering, vol. 2019, Article ID 7419752, 11 pages, 2019.

[6] Y. J. Yang and D. P. Ma, "Experimental research on energy evolution properties of coal sample failure under triaxial unloading testing," Journal of Mining \& Safety Engineering, vol. 35, no. 6, pp. 1208-1216, 2018.

[7] L. Wang, J. F. Liu, H. T. Yang, H. N. Ren, and M. Nie, "Experimental research on mechanical properties of deeply buried marble under unloading conditions," Journal of Sichuan University: Engineering Science Edition, vol. 46, no. 2, pp. 46-51, 2014.

[8] L. M. Zhang, Z. Q. Wang, J. X. Wang, and Q. Lu, "Experimental study on the rock behavior under unloading condition," Journal of Sichuan University: Engineering Science Edition, vol. 38, no. 3, pp. 34-37, 2006. 
[9] Y. M. Li, L. S. Hao, S. L. Wei, and X. X. Zhai, "Research on coal deformation and failure mechanical parameters in different stress way of loading and unloading test," Coal Technolog, vol. 25 , no. 12, pp. 129-131, 2006.

[10] K. Zhang, H. Zhou, P. Z. Pan, L. F. Shen, X. T. Feng, and Y. G. Zhang, "Characteristics of strength of rocks under different unloading rates," Rock and Soil Mechanics, vol. 31, no. 7, pp. 2072-2078, 2010.

[11] M. C. He, J. L. Miao, and J. L. Feng, "Rock burst process of limestone and its acoustic emission characteristics under truetriaxial unloading conditions," International Journal of Rock Mechanics and Mining Sciences, vol. 47, no. 2, pp. 286-298, 2010.

[12] X. Zhou, Q. Qian, and B. Zhang, "Zonal disintegration mechanism of deep crack-weakened rock masses under dynamic unloading," Acta Mechanica Solida Sinica, vol. 22, no. 3, pp. 240-250, 2009.

[13] J. Browning, P. G. Meredith, C. E. Stuart, D. Healy, S. Harland, and T. M. Mitchell, "Acoustic characterization of crack damage evolution in sandstone deformed under conventional and true triaxial loading," Journal of Geophysical Research: Solid Earth, vol. 122, no. 6, pp. 4395-4412, 2017.

[14] R. Q. Huang and D. Huang, "Evolution of rock cracks under unloading condition," Rock Mechanics and Rock Engineering, vol. 47, no. 2, pp. 453-466, 2014.

[15] X. Li, W. Cao, Z. Zhou, and Y. Zou, "Influence of stress path on excavation unloading response," Tunnelling and Underground Space Technology, vol. 42, pp. 237-246, 2014.

[16] Q. Sun, F. B. Duan, and H. P. Xie, "Study on fractal dimension evaluation measurement of coal rock blasting," Chinese Journal of Rock Mechanics and Engineering, vol. 19, no. 4, pp. 505-508, 2000.

[17] T. J. Li, Y. H. Wang, M. Y. Zhang, Q. G. Li, Y. Xu, and G. H. Tan, "Fractal properties of crack in rock and mechanism of rockburst," Chinese Journal of Rock Mechanics and Engineering, vol. 19, no. 1, pp. 6-10, 2000.

[18] Q. Y. Wang, D. P. Li, and J. L. Wei, "Joint distribution effect on axial compressive strength and deformation scale effects of rock masses," Chinese Journal of Rock Mechanics and Engineering, vol. 27, no. 9, pp. 1852-1857, 2008.

[19] T. Deng, L. D. Yang, and W. F. Han, "Influence of loading form on distribution of marble fragments," Journal of Tongji University: Nature Science, vol. 35, no. 1, pp. 10-14, 2007.

[20] H. P. Xie, Introduction to Fractal Rock Mechanics, pp. 242-243, Science Press, Beijing, China, 1997.

[21] M. C. He, G. X. Yang, J. L. Miao, X. N. Jia, and T. T. Jiang, "Classification and research methods of rockburst experimental fragments," Chinese Journal of Rock Mechanics and Engineering, vol. 28, no. 8, pp. 1521-1529, 2009. 